\title{
Multinodular Adrenal Hyperplasia
}

National Cancer Institute

\section{Source}

National Cancer Institute. Multinodular Adrenal Hyperplasia. NCI Thesaurus. Code

C127164.

A subtype of adrenal hyperplasia, based on histopathologic features, in which there are multiple nodules. 